\title{
Mesenchymal Stem Cell Immunomodulation: A Novel Intervention Mechanism in Cardiovascular Disease
}

\section{Yueyao Wang}

First Teaching Hospital of Tianjin University of Traditional Chinese Medicine https://orcid.org/00000002-2071-4997

\section{Zhongwen Qi}

First Teaching Hospital of Tianjin University of Traditional Chinese Medicine

\section{Zhipeng Yan}

First Teaching Hospital of Tianjin University of Traditional Chinese Medicine

Nan Ji

First Teaching Hospital of Tianjin University of Traditional Chinese Medicine

Xiaoya Yang

First Teaching Hospital of Tianjin University of Traditional Chinese Medicine

\section{Dongjie Gao}

First Teaching Hospital of Tianjin University of Traditional Chinese Medicine

Junping Zhang ( $\nabla$ tjzhtcm@163.com )

First Teaching Hospital of Tianjin University of Traditional Chinese Medicine

\section{Meng Li}

First Teaching Hospital of Tianjin University of Traditional Chinese Medicine

\section{Research}

Keywords: Immune Regulation, Inflammation, Cardiovascular Disease, Immunocytes, Mesenchymal Stem Cells

Posted Date: February 10th, 2021

DOl: https://doi.org/10.21203/rs.3.rs-168163/v1

License: (c) (i) This work is licensed under a Creative Commons Attribution 4.0 International License. Read Full License

Version of Record: A version of this preprint was published at Frontiers in Cell and Developmental Biology on January 12th, 2022. See the published version at https://doi.org/10.3389/fcell.2021.742088. 


\section{Abstract}

Mesenchymal stem cells (MSCs) belong to the family of pluripotent stem cells, which have an obvious multi-directional differentiation potential and can regulate the immune response of the organism by influencing immune cell subsets, thus they have excellent prospects for application in inflammation, immune diseases, and organ transplantation. Numerous studies have shown that MSCs are a promising strategy for the treatment of cardiovascular disease by modulating immune cell subsets and coordinating local and systemic innate and adaptive immune responses, thereby enabling the formation of a stable inflammatory microenvironment in damaged cardiac tissues. In this review, we summarize the mechanisms by which MSCs interact with immune cells and exert immunomodulatory effects, and explain the therapeutic effects of this mechanism in the treatment of cardiovascular diseases. A feasibility analysis is provided for the application of MSCs in cardiovascular diseases.

\section{Background}

Mesenchymal stem cells are an extremely powerful matrix cells with strong differentiation and selfsustaining ability, which can be produced in many organizations, such as endometrium, bone marrow, umbilical cord, and fat. The pluripotency of mesenchymal stem cells makes it a great choice for modern medical organ transplantation and immune response(1). Currently, mesenchymal stem cells are considered as a potential new option for the treatment of autoimmune and inflammatory diseases. At the same time, numerous experimental and clinical studies have confirmed the great utility of MSCs in cellular immunomodulation, organ-specific and systemic inflammatory diseases. Studies have shown that MSCs can modulate the body's immune response by regulating macrophage polarization, producing immunosuppressive molecules, and stimulating metabolites(2).

Cardiovascular disease is now the leading cause of death worldwide(3). It is an ischemic disease that occurs in the heart and its surrounding vessels due to hyperlipidemia, atherosclerosis and other lesions. The risk factors are smoking, obesity, diabetes, genetic predisposition, hyperlipidemia and hypertension(4). Therefore, it is extremely common in the middle-aged and elderly population and is characterized by high pathogenicity and high mortality. Mesenchymal stem cells have the ability to modulate immune system activity and anti-inflammatory capacity, and have become a new approach to repair damaged myocardium and treat cardiovascular diseases such as myocardial infarction. In a 2011 meta-analysis of preclinical animal studies of cell therapy for ischemic heart disease, MSC therapy was shown to be safe and effective and was associated with improvements in left ventricular ejection fraction. Studies have shown that MSCs have significant effects in repairing damaged myocardium, promoting myocardial regeneration, and restoring normal cardiac function. Therefore, it can play a role in protecting cardiac function and treating cardiovascular diseases. It can secrete cytokines such as epidermal growth factor through paracrine pathway to promote myocardial repair, and can also regulate the expression of immune cells and related inflammatory cells to alleviate the inflammatory response after myocardial injury(5). This review explains the immunomodulatory effects of MSCs and their role in 
cardiovascular diseases, starting from the mechanisms involved in the regulation of immune responses by MSCs.

\section{Overview Of Mesenchymal Stem Cells}

Mesenchymal stem cells are pluripotent stem cells that were first discovered in the late 1960s by Alexander Friedenstein, who discovered that MSCs are early cells in mesodermal development and have a strong differentiation potential. Mesenchymal stem cells are in the form of fibroblasts and can proliferate in vitro as adherent cells $(6,7)$. Is notable for the fact that the primary cells of the different sources of the interstitial stem cells are derived from the capillary, arteries and veins of the body, but their respective biological characteristics are not identical(8). At present, there are four kinds of human mesenchymal stem cells, which are human umbilical cord mesenchymal stem cells, adipose tissue mesenchymal stem cells, bone marrow mesenchymal stem cells and placental mesenchymal stem cells. Among them, bone marrow mesenchymal stem cells are the most widely used and the most convenient one(9). MSCs are highly proliferative and self-renewing, and can differentiate into neural cells, cardiomyocytes, blood cells, and other cells according to different stages of development and different environments. Studies have shown that the interaction between MSCs and the extracellular matrix can effectively promote the transformation of MSCs into hepatocytes(10). Mesenchymal stem cells were found to differentiate into chondrocytes induced by hypoxic conditions(11). The adipose mesenchymal stem cells can also differentiate into neuronal cells, which can further differentiate into astrocytes, oligodendrocytes, and functional neurons(12). Mesenchymal stem cells can repair tissue damage through their differentiation function. In in vitro experiments, MSCs expand rapidly, are easy to culture, and can be induced to develop into directional cells, therefore, they are of great importance for tissue repair and gene therapy. The ability to express a variety of characteristic immune phenotypes, such as CD105\CD105\CD90 \ CD44\CD71(13).

Bone marrow mesenchymal stem cells can be isolated from almost all tissues, the extracellular matrix enzymes in the bone marrow are decomposed to extract more MSCs from the small triangular bone cavity, specifically the tibia and femur of mice, which are first collected and digested with collagenase to obtain a single cell suspension. Bone marrow MSC can secrete a variety of bioactive factors, including cytokines, chemokines, inflammatory factors, and extracellular vesicles (exosomes), thereby exerting angiogenic, anti-apoptotic, anti-fibrotic, antioxidant, and immunomodulatory effects. MSC has been shown to secrete cytokines such as CCL2(Chemokine C-C motif ligand 2), CCL5 (Chemokine C-C motif ligand 5), IGF-1 (Insulin-like growth factor-1), IL-6 (Interleukin-6) and VEGF(Vascular endothelial growth factor), which are involved in cell and tissue development, differentiation, and death(14). MSCs can also immunomodulate by secreting cytokines such as IL-6, IL-10(Interleukin-10), prostaglandin E2(PGE2), and transforming growth factor Beta(TGF- $\beta$ )(15). It can also be involved in intercellular communication through the secretion of exosomes with immunomodulatory properties, thereby facilitating the immune system's role in recognizing and eliminating antigenic foreign bodies(16). The chemokines of bone marrow mesenchymal stem cells are mainly CXC chemokine receptor 3 (CXCR3) and CC chemokine receptor 5 (CCR5) ligands, as well as CXC chemokine ligand 9(CXCR9), CXC chemokine ligand 
10(CXCR10) and CXC chemokine ligand 11(CXCR11). They are well-known immune cell chemotactic agents and can regulate immune cells, such as T lymphocytes(17). MSC can regulate the immune response by regulating the activities of $T$ cells and $B$ cells, thus inhibiting cell apoptosis. At the same time, MSC can interact with the immune system, mainly for immunosuppression, and can inhibit immune cells such as lymphocytes, antigen-presenting cells, and natural killer cells. In recent years, MSCs have been used in the treatment of autoimmune diseases, often with great therapeutic effects.

Table 1

Key Factors Associated with MSC Immunomodulation

\begin{tabular}{|c|c|}
\hline $\begin{array}{l}\text { Key } \\
\text { Factors }\end{array}$ & Role in Mesenchymal Stem Cell Immunomodulation \\
\hline IL-2 & Inhibition of NK Cell Proliferation and Differentiation(18). \\
\hline IL-6 & Promotes B-cell proliferation and differentiation(19). \\
\hline IL-10 & $\begin{array}{l}\text { Inhibition of DC Cell Differentiation(20). Promotes the proliferation of B cells and increases } \\
\text { the number of B-reg cells producing IL-10(21). }\end{array}$ \\
\hline PGE2 & $\begin{array}{l}\text { Inhibition of DC Cell Differentiation(22). Down-regulation of T-lymphocyte expression(23). } \\
\text { Induced M2 Phenotype of Macrophages(24). }\end{array}$ \\
\hline TGF- $\beta$ & Inhibits proliferation and activation of DC cells(25). \\
\hline TNF-a & Promotes the expression of B lymphocytes(26) \\
\hline \multicolumn{2}{|c|}{$\begin{array}{l}\text { Abbreviations: IL-2: Interleukin- 2; NK cell: Natural Killer Cells; IL-6: Interleukin-6; B-cell: B- } \\
\text { Lymphocytes; IL-10: Interleukin-10; DC cell: Dendritic cells; PGE2: Prostaglandin E2; TGF- } \beta \text { : Growth } \\
\text { Factor Beta; TNF-a:Tumor Necrosis Factor Alpha }\end{array}$} \\
\hline
\end{tabular}

\section{Modulation Of Different Immune Cells By Mesenchymal Stem Cells}

\section{Interaction with Antigen presenting cells}

Antigen-presenting cells include dendritic cells, monocytes, and B cells(27). Antigen-presenting cells are important players in the immune system. Once an infection occurs, the body's innate immune system is stimulated to begin the inflammatory process and prevent the infection from spreading. Therefore, an adaptive immune response is necessary to clear the pathogen and the key to adaptive immunity lies in the antigen-presenting cells(28).

\subsection{Macrophages}

Macrophages can be obtained from mononuclear cell bank of blood, bone marrow, spleen, tissue progenitor cells or local .In the proliferation of. It is an important part of the human body, and also the vanguard of human immunity. It reacts to external stimulation and physiological changes. It can perform different functions in the body's immune response, such as regulating cell apoptosis, phagocytosis of pathogens, remodeling extracellular matrix, activating other immune cells and so on. Macrophage 
activation depends on a variety of metabolic pathways, such as glycolysis, tricarboxylic acid cycle, pentose phosphate pathway, fatty acid oxidation, fatty acid synthesis and amino acid metabolism. The above pathways cooperate to complete the function of cell effector and regulate the polarization of macrophages. Macrophages can be polarized into two different phenotypes: M1 phenotype and M2 phenotype(29, 30).

Among the two phenotypes, M1 polarization is known as the classic polarization, which can promote the secretion of pro-inflammatory factors, thus promoting antibacterial reaction, while M2 polarization is activated by IL-4(Interleukin-4) and IL-13(Interleukin-13), which is generally considered to have immunosuppressive effect(31). BMSC (Bone marrow mesenchymal stem cells) can inhibit macrophage activation and transform M1 phenotype to M2 phenotype. BMSC was injected into the sulfur mustard induced acute lung injury mouse model, and it was found that the proportion of anti-inflammatory M2 macrophages and the proportion of M1 macrophages were significantly increased and decreased in BMSC-treated mice compared with the sulfur mustard group. At the same time, the expression of TRL4(Toll-like receptor 4) was significantly increased. This indicates that BMSC can inhibit the breakdown of macrophages into M1 macrophages through TRL4 signaling pathway, promote their transformation into M2 macrophages, and exert its anti-inflammatory effect(32). Mesenchymal stem cells can secrete vesicles with a diameter of 40-100 nm, which are called exosomes. Exosomes can carry large amounts of proteins, cytokines, miRNAs, DNA and other biologically active substances. Exosomes from bone marrow MSCs were extracted, and some of them were treated with LPS(Lipopolysaccharide), and it was found that both the normal MSC exosomes and the LPS-treated MSC exosomes significantly reduced the positive rate of the M1 macrophage protein marker CD11 and increased the positive rate of the M2 macrophage protein marker CD206. This indicates that exosomes derived from MSCs can regulate macrophage polarization by inhibiting the NFKB (Nuclear factor kappa-B) pathway and activating the Akt1/Akt2囚Serine threonine-specific protein kinase囚pathway, thereby reducing postinfarction inflammation and cardiomyocyte apoptosis(33). Exosomes extracted from diabetic mouse mesenchymal stem cells can reverse the expression levels of $\mathrm{M} 1$ and $\mathrm{M} 2$ cellular protein marker in diabetic mice. miRNAs contained in exosomes, such as miR-23a and miR-125b, can synergistically target the TLR4/NF-KB signaling pathway. Thus exerting anti-inflammatory effects and promoting neurovascular remodeling and functional recovery in mice with peri-diabetic lesions(34). Mesenchymal stem cells can secrete TGF- $\beta$, which activates the Akt/Fox01(Forkhead box transcription factor 01) pathway in macrophages in mice with high body oxygen levels, alveolar fibrosis and pulmonary vascular remodeling(35). At the same time, recruitment of macrophages also plays a very important role in the immune regulation mediated by mesenchymal stem cells. Among them, BMSC can secrete a large number of chemokines, thus acting as the main chemotactic agent of macrophages and mediating the immune regulation of macrophages. For example, MSCs mediate immunomodulation through INOS (Inducible nitric oxide synthase) and COX2(Cyclooxygenase 2)-dependent pathways to increase PGE2 production, which in turn increases IL-10 production in macrophages by binding to EP2(Prostaglandin E Receptor 2) and EP4(Prostaglandin E Receptor 4) receptors(36). Similarly, BMSC secretory factors can polarize mouse peritoneal macrophages to the IL-10(Interleukin-10) phenotype, in which the inflammatory 
chemokines CCL2 and CXCL2, secreted in BMSC, play an important role(37). Yap protein in Hippo pathway can regulate inflammatory response. Mesenchymal stem cells can control NLRP3 (Recombinant NLR Family, Pyrin Domain Containing Protein 3 )by promoting Hippo pathway in macrophages, regulating the interaction between yap and $\beta$ - catenin, and regulate the activation of NLRP3 mediated by XBP1(X-box binding protein 1), so as to recombine macrophage M2 phenotype, so as to achieve the purpose of treating liver aseptic inflammatory injury(38). IL-10bmsc can inhibit the antigen presentation ability of macrophages, but this effect can be eliminated when Incrna003946 in macrophages is knocked out, which indicates that BMSC can play an immunomodulatory role by up regulating Inc RNA 003946 in CD68 + antigen-presenting macrophages(39). This shows that MSCs can interact with macrophages and act through inflammatory factors such as TGF- $\beta$ and IL-10 to modify the phenotype of macrophages from a pro-inflammatory M1 phenotype to an anti-inflammatory M2 phenotype

\subsection{Dendritic cell}

Dendritic cells (DCs) are specialized antigen-presenting cells, named for the many dendritic or pseudopod-like projections that extend out as they mature. They are present in lymphoid and nonlymphoid organs as resident or migrating cells(40). Dendritic cells are a heterogeneous population of leukocytes composed of different subpopulations that drive specific types of immune responses and can initiate and modulate adaptive immune responses(41). Human granulocyte-macrophage progenitor cells have been shown to have the potential to differentiate DC cells, and DC cell precursor cell populations can migrate from the bone marrow, enter peripheral lymphoid organs such as the tonsils via the bloodstream, and eventually differentiate into DC cells(42). DC cells are divided into three subpopulations, which are : plasmacytoid DC, myeloid/conventional DC1 and myeloid/conventional DC2(43).

MSCs can inhibit the proliferation of dendritic cells, thus exerting immunomodulatory and immunosuppressive effects(25). MSCs with high expression or knockdown of HGF (Hepatocyte growth factor) were co-cultured with mouse bone marrow-derived DCs for 3 days using the transwell system, and then LPS-induced ALI (Acute lung injury) mice were treated with MSCs with high expression or knockdown of HGF or MSCs for $24 \mathrm{~h}$. The phagocytosis, accumulation, and maturation of dc cells were examined, and MSCs were found to induce m-DCs cells to differentiate into regulatory DCs cells, and MSCs treatment reduced DC cell aggregation and maturation and attenuated lung histopathological injury, and this process was associated with the HGF/AKT pathway(44). DC cells have numerous

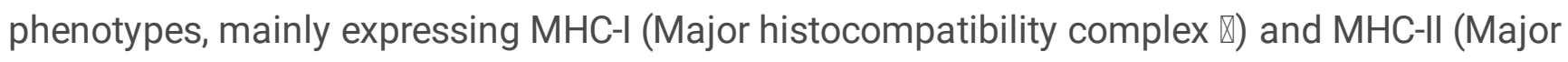
histocompatibility complex II) class molecules as well as CD370, CD207, CD205, CD1a, CD11c, CD11b, CD83, CD40(45). DC cells were co-cultured with mouse MSC after TNF-a(Tumor necrosis factor Alpha) treatment, and the presence of MSC caused ovalbumin-stimulated DCs to inhibit the proliferation of antigen-specific CD4+ T cells or the ability of DCs to exhibit MHC-II-like peptide complexes that could be recognized by specific antibodies, and the migration of mature DC cells to the chemokine CCL19(Chemokine C-C motif ligand19) was significantly reduced in MSC, indicating that MSC affected the antigenic presentation and migration of DC cells(46). DC cells were co-cultured with MSCs and 
studied for their bidirectional regulatory effects and the key molecules associated with them, and the results showed that when osteopontin activity was blocked, the effects of DC conditioned cultures on MSC differentiation and CCL5 induction could be prevented, and the direct addition of exogenous PGE2 could inhibit DCs from producing osteopontin. It may be that MSCs modulate the signal according to their activation state and also participate in the DC regulation of MSC differentiation, where PGE2 also plays an important role(47).

DC cells are the target of immunomodulatory MSCs in type I diabetes. M-DC(Mature dendritic cells) cells derived from monocytes in diabetic patients were co-cultured with MSCs and MSC-derived exosomes, and DC cells under MSC and MSC-derived exosomes showed an immature phenotype and increased expression of IL-10 and IL-6. This suggests that MSCs induce immature IL-10 secretion from DCs in vitro, thereby promoting the anti-inflammatory and regulatory responses exerted by MSCs(48). Dendritic cells can initiate T-cell immunoregulation, and they can regulate T-cell differentiation toward Th1, Th2, Th17, or Treg subpopulations. Dendritic cells can also indirectly regulate T-cell subpopulation differentiation by activating intrinsic lymphocytes to produce regulatory cytokines that conform to T-cell subpopulation norms(49). Immature dendritic cells (im-DCs) and lipopolysaccharide (LPS)-treated mature dendritic cells were co-cultured with MSCs for $48 \mathrm{~h}$. The expression of CD11c, CD80, CD86, interleukin 6, tumor necrosis factor- $a$, and interferon- $\gamma$ was found to be decreased, while CD11b, IL-10, and transforming growth factor$\beta$ (TGF- $\beta$ ) expression was significantly increased and stimulated splenocytes to produce markers of Tregs (Foxp3, CD4 and CD25), suggesting that MSCs induce a shift from immature and mature DC phenotypes

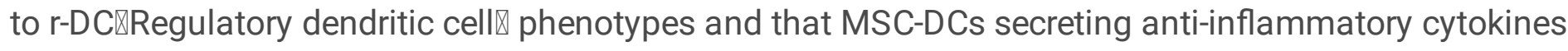

(IL-10 and TGF- $\beta$ ) play a similar role to r-DCs, leading to the activation of Tregs(50). Bone marrow-derived dendritic cells, were co-cultured with MSCs-derived exosomes $(100 \mu \mathrm{g} / \mathrm{ml})$ to observe the effects of MSCderived exosomes on the induction of tolerant dendritic cells in mice in order to study the effects of MSCderived exosomes on the induction of tolerant dendritic cells in mice. MSC-derived exosomes were found to significantly decrease the expression of lipopolysaccharide-treated DC cell surface markers and decrease the release of IL- 6 and increase the release of IL-10 and TGF- $\beta$. Exosomes from bone marrow MSC-treated DC cells also reduced lymphocyte proliferation, thus suggesting that exosomes may be an important regulator of DC cell-induced immune responses(51). Thus, MSCs can exert immunomodulatory effects by regulating the phenotypic transformation of dendritic cells and inhibiting the proliferation of dendritic cells, a process associated with cytokines such as IL-10, TGF- $\beta$, IL-6, and PGE2.

\section{Lymphocyte}

\subsection{T lymphocytes}

MSCs can mediate immune responses by regulating the activity of $\mathrm{T}$ lymphocytes, which are referred to as $T$ cells. $T$ cells are immune cells that originate from the bone marrow and differentiate and mature in the thymus gland. T cells are essential for the body's immune response, maintenance of homeostasis, maintenance of immune memory, recognition of pathogens, tumors, and antigens(52). T lymphocytes do 
not produce antibodies, but act directly to kill target cells, assist or inhibit B cells to produce antibodies, and respond to specific antigens(53).

Studies have shown that mesenchymal stem cells can regulate immunity through T lymphocytes. BMSC can induce the apoptosis of T lymphocytes. When BMSC was co cultured with T lymphocytes, it was found that BMSC could significantly inhibit the proliferation of T lymphocytes. At the same time, when BMSC was co cultured with CD 4 cells and CD8 cells, it was found that bone marrow mesenchymal stem cells could inhibit CD4 and CD8 lymphocytes(54). In the presence of pathogenic microbial stimuli, it is able to provoke an immune response of innate immunity and produce interferon, IFN $\mathrm{Y}$ (interferon $\mathrm{Y}$ ) is a member of the type II interferon, which is widely involved in the immune response. BMSC was found to promote phenotypic transformation of T lymphocytes. In an in vitro experiment, BMSC was administered to alum-treated mice and was found to inhibit OVA(Ovalbumin)/alum sensitization and subsequent excitation resulting in Th2-mediated eosinophilic pneumonia. CD4 converts to the Th1 phenotype and inhibits Th2-mediated allergic airway inflammation through an IFN $\gamma$-dependent process(55). The results showed that the differentiation and function of th 17 were significantly inhibited after low, medium and high doses of exosomes, and the content of histone H3K27me3(Trimethylatin $f$ iysine $27 \mathrm{n}$ histne 3 ) also changed accordingly. This indicates that exosomes from MSCs can inhibit the differentiation of Th17 cells in ulcerative colitis, which is achieved by regulating H3K27me3(56). Human urine-derived MSCs were co-cultured with $\mathrm{CD} 4+$ cells and found to inhibit CD4+ proliferation, resulting in downregulation of Th1/Th17 immune responses in a PGE2-dependent manner(57). On the other hand, Terg cells, are a type of regulatory $T$ cell, a subset of $T$ cells that regulate autoimmunity in the body Terg cells can be divided into naturally occurring and induced natural regulatory $T$ cells that suppress abnormal/overactive immune responses to auto and non-auto antigens to maintain immune homeostasis(58). Terg cells can act through cell-to-cell contact and also modulate inhibitory cytokines, such as IL-10, as well as modulate body immunity by interacting with antigen-presenting cells(59). Therefore, Terg cells play an important role in maintaining immune homeostasis and preventing autoimmune diseases and suppressing rejection. At the same time, the mesenchymal stem cells can also block $t$ cell blocks in $\mathrm{g0} / \mathrm{g} 1$, inhibiting the proliferation of t cells. Mesenchymal stem cells can induce Terg production(60). researchers used an autoimmune EAE(Encephalomyelitis) mouse model to assess the therapeutic effects of exosomes secreted by human bone marrow MSCs in multiple sclerosis and found that the number of CD4+CD25+FOXP3+ regulatory $T$ cells on the spinal cord of mice was upregulated after intravenous injection of IFN Y (IFN Y-Exo)-stimulated MSCs-derived exosomes(61). CD4(+) lymphocytes and MSCs were co-cultured with activated or silenced TLR3(Toll-like receptor3) or TLR4, and then their Treg cell generation levels were measured. This phenomenon of enhanced Treg induction is cell contact-dependent and is associated with increased gene expression of the Notch ligand Delta-like 1. Inhibition of Notch signaling eliminated the enhanced Treg levels in MSCs. This suggests that MSC-activated TLR3 or TLR4 increases Treg induction through the Notch signaling pathway(62). Thus, MSCs are able to intervene in the activation, proliferation, subpopulation, and phenotypic transformation of $\mathrm{T}$ lymphocytes, as well as to increase the level of Treg cells, thus exerting an immunomodulatory effect. Among them, cytokines such as IFN Y and PGE2 also play a role. 


\subsection{B lymphocytes}

B lymphocytes are derived from pluripotent stem cells of bone marrow, mainly located in human lymph nodes and spleen. The differentiation of B cells can be divided into five stages: pre-B cells, immature $B$ cells, activated $B$ cells and plasma cells. $B$ cells can regulate the immune response, which is related to its ability to produce antibodies. Mature B cells can become activated B cells after being stimulated by antigen, and then become plasma cells to secrete and synthesize antibodies, so as to perform humoral immunity. Its immunosuppression is related to the secretion of IL-10 by B cells $(63,64)$. B cells can also express congenital pattern recognition receptors (including toll like receptors), complement receptors, Epstein Barr virus receptors and cytokine receptors(65). The specific surface molecules of B cells are CD19, CD20, CD21, CD79a, CD40. among them, the cytoplasmic domains of CD79a and CD79b contain highly conserved motifs of tyrosine phosphorylation and Src family kinase docking. These motifs are essential for initiating BCR (B-cell receptor)signal and B cell activation $(66,67)$.

Therefore, B lymphocytes can produce antibodies to mediate the immune response, and can also produce a large number of cytokines to regulate immunity and participate in inflammatory response. However, $B$ cells need to activate $T$ cells for immune response. Mesenchymal stem cells can affect the activity of $B$ cells by the immunomodulators such as cytokines, chemokines and growth factors. In order to study the immunomodulatory effect of MSC derived exosomes on B cells and other lymphocytes, MSC was co cultured with IEC (Immunosuppressive towards effector cells )such as cd3post cells, cd19posb cells and cd56posnk cells. The resting MSCs could not inhibit B cell division. However, after pretreated with IFN - $Y$ and TNF - a (Tumor necrosis factora), MSCs obtained significant immunosuppressive effect, and the proliferation of $B$ cells was reduced by more than $80 \%$ The exosomes derived from stem cells may regulate $B$ lymphocytes through paracrine action to achieve immune regulation(68). In a mouse model of colitis, intraperitoneal injection of human bone marrow stem cells can enhance the immunomodulatory effects of B cells by upregulating IL-10 expression, induce a regulatory B cell (Breg) population characterized by CD23 and CD43 phenotypic markers, increase the number of CD23+CD43+Breg cells, and reduce the clinical and pathological severity of colitis in mice(69). In a clinical study investigating chronic graft-versus-host disease with MSC, 38 patients received bone marrow MSC at least twice at 4week intervals, with follow-up examinations every 3 months until 12 months after the first MSC infusion. The number of CD27+ and memory B lymphocytes was significantly increased in patients with chronic graft-versus-host disease after MSC treatment, while plasma levels of BAFF(B-cell activating factor) on peripheral B lymphocytes decreased and BAFF-R(BAFF receptor) expression increased. This indicates that the therapeutic mechanism of MSC for chronic graft-versus-host disease is accompanied by changes in naïve and memory B-cell subsets, and regulates plasma BAFF levels and BAFF-R expression on Blymphocytes(70). A multicenter prospective cohort study of mesenchymal stem cells in the treatment of bronchiolitis obliterans after allogeneic hematopoietic stem cell transplantation showed that compared with the non bone marrow mesenchymal stem cell group, patients in the bone marrow mesenchymal stem cell group had a better change in FEV1 (Forced Expiratory Volume in the first second) reduction rate compared with the non bone marrow mesenchymal stem cell group, The production of CD5 + B cells by IL-10 was also significantly increased(71). In a rat model of intervertebral disc injury, we transplanted 
MSC veins into rats and found that MSC transplantation resulted in an increase in the number of Pax5(Paired-box 5)+B lymphocytes and an increase in MHC II+ and CD4+ cells, as well as an upregulation of the inflammatory cytokines IL-2, IL-4, IL-6, and IL-10, and a down-regulation of IL-13 and TNF-a compared to controls(72). In a study on the biology of bone marrow-derived mesenchymal stem cells in primary immunodeficient patients, the researchers performed a detailed analysis of the biological characteristics of bone marrow-derived mesenchymal stem cells from 33 children with primary immunodeficiency (PID-MSCs) and found that all PID-MSCs exhibited clonogenic and proliferative capacity, morphological and immune phenotypes similar to those of HD-MSCs (Bone marrow-derived mesenchymal stem cells from healthy child donors) are comparable, and are able to inhibit cells such as $B$ cells, and inhibit the transformation of monocytes into immature dendritic cells(73). In a study of the effects of mesenchymal stem cells derived from human full-term placental amniotic membrane (hAMSC) and the conditioned media-derived mesenchymal stem cells (CM-hAMSC) generated from their culture on $B$ cell proliferation and differentiation, it was found that both hAMSC and CM-hAMSC strongly inhibited the proliferation of CpG-activated B cells. In addition, CM-hAMSC also blocked B cell differentiation, resulting in an increased proportion of mature $B$ cells and decreased antibody-secreting cell formation (74). CFSE-labeled mouse splenocytes were cultured in mesenchymal stem cells and human bone marrow-derived mesenchymal stem cells from trophoblast-like intermediate human embryonic stem cells, and B cells were stimulated with anti-IgM antibodies. Dependent B-cell proliferation indicates that MSCs produced in trophoblast-like intermediate human embryonic stem cells have immunosuppressive effects on B-lymphocytes, as do human bone marrow MSCs, and that trophoblast-like intermediate human embryonic stem cells do not increase the expression of inflammatory mediators in response to IFN $\mathrm{Y}$ and can constitutively express high levels of the immunosuppressive ligand PD-L1 (Programmed cell death 1 ligand 1)(75). Therefore, MSCs, with respect to $B$ lymphocytes, mainly play an immunosuppressive role, inhibiting the proliferation of B lymphocytes through inflammatory factors such as IFN- $y$ and TNF-a.

\subsection{NK cells}

NK cells, also known as natural killer cells, are an important immune cell produced by the body and are involved in hypersensitivity reactions. NK cells can be expressed as CD3-CD56 lymphocytes in humans. NK cells have many receptors that, when used alone or in combination, trigger their effector functions. CD314, NCR(the Natural cytotoxic receptor), CD226, and CD16 are highly characterized receptors for NK cell activation. These receptors tightly regulate the activity of NK cells, enabling them to distinguish between "normal" and "dangerous" cells. In summary, NK activation depends on the balance between activating and inhibiting signals triggered by the receptor-bound ligand. When activation signals prevail, NK cells respond, whereas when inhibitory signals are strong, NK cells do not respond $(76,77)$.

Mesenchymal stem cells can be immunomodulated by NK cells. Bone marrow MSCs have been shown to promote degranulation of NK cells, which can occur when NK cells are in close proximity to target cells due to components such as perforin and granzyme, and degranulation is related to the killing activity of NK cells, which can directly kill target cells and exert the effect of innate immunity(78). NK cells of peripheral blood mononuclear cell origin from healthy donors were incubated with SKO-007 (J3) cells 
(Human myeloma cells), some of which were untreated and some of which were incubated with BMSC$\mathrm{CM}$ for $72 \mathrm{~h}$, as target cells for degranulation assay. The results showed that CD107a expression was significantly elevated in the combined BMSC incubation group, indicating enhanced degranulation of NK cells, and the same results were also observed in patient-derived NK cells against SKO-007 (J3) cells or autologous CD138+ plasma cells treated with BMSC-CM(79). Bone marrow MSCs also modulate the immune activity of hepatic NK cells, and Con A (Concanavalin A) was injected into C57 to model Con A liver injury. The results showed that bone marrow MSC transplantation reduced factors and cytotoxic substances in mouse liver, suggesting that bone marrow MSC can reduce the activation of hepatic NK cells(80). More than a simple static inhibition of MSCs and NK cells, studies have shown that activation of MSCs between tissues can also modulate the immune function of NK cells. Interferons to enhance NK cell effector function, while at subsequent time points, TGF- $\beta$ and IL-6 limit NK cell effector function and terminate the inflammatory response by inducing a regulatory senescence-like NK cell phenotype(81). MSCs can also inhibit NK cells by inhibiting IL-2. Negatively selected NK cells were activated with IL-2 and plated on irradiated MSCs at a ratio of 4:1 (NK/MSC) (which proved to be the most optimal for NK-MSC inhibition). 7 days later, the phenotype, cytotoxicity, proliferation and cytokine production of NK cells were examined and MSCs were found to be It not only inhibits cytokine-induced NK cell proliferation, but also inhibits effector functions such as cytotoxicity and cytokine production by NK cells(82). NK cells and MSCs also have a bi-directional role in regulating and influencing NK cell activity. Pre-activated MSCs were found to significantly inhibit the expression of activation markers in hepatic NK cells after cotransplantation with pancreatic islets to regulate NK cell activity(83). Meanwhile, NK cells can also promote the homing effect of MSCs. MSCs were co-cultured with human bone marrow MSCs and NK cells fresh from healthy donors, and then the supernatant of MSC-NK cell co-culture was tested and found to induce MSC recruitment to the damaged tissue sites(84). MSCs can interfere with the degranulation of NK cells and thus have an inhibitory effect on the proliferative killing activity of NK cells, which is associated with cytokines such as IL-2 and IFN-y.

\section{Immunomodulation Of Mesenchymal Stem Cells In Cardiovascular Disease}

\section{Myocardial infarction}

Myocardial infarction is a severe narrowing of the coronary arteries, resulting in a dramatic reduction or interruption of the blood supply, which leads to myocardial necrosis due to persistent ischemia. When the duration of ischemia is too long, it can cause the death of myocardial cells and symptoms such as severe angina pectoris and arrhythmia, which can be life-threatening in severe cases.

MSCs can reduce cardiac dysfunction after myocardial infarction through their immunomodulatory effects. Intravenous MSCs were administered to mice in a model of myocardial infarction and were found to eliminate the progressive deterioration of left ventricular end-diastolic volume and left ventricular endsystolic volume and significantly reduce the number of natural killer cells and neutrophils in the heart and spleen(85). IL-33( Interleukin-33) is a tissue-derived nuclear cytokine of the IL-1 family, which functions as 
an alarm signal released in response to cell injury or tissue damage. It targets mast cells, regulatory $T$ cells, NK cells, neutrophils and macrophages in the body, making it an extremely important immunomodulatory molecule(86). MSCs transfected with empty plasmids were co-cultured with MSCs transfected with IL33 with T cells and macrophages, and T cell proliferation and polarization of macrophages were observed. The experiments showed that IL33-MSCs decreased T cell proliferation, promoted the differentiation of CD4+ T cells into CD4+IL-4+ Th2 cells, and enhanced the polarization of CD206+ macrophages, and the myocardial fibrosis, inflammation, and cardiac function recovered better in rats treated with IL33-MSCs(87). IL-10 is a multipotent cytokine with anti-inflammatory properties that prevents host damage by limiting the immune response to pathogens and can exert immunosuppressive or immunostimulatory effects in a variety of cells(88). IL-10-transfected MSCs were injected into MI rats, and in vitro glycogen deprivation revealed that overexpression of IL-10 in MSCs enhanced cell viability and increased IL-10 secretion. The infarct size, myocardial injury and apoptosis were reduced, and systemic and local inflammation were reduced(89). In a murine model of acute myocardial infarction, MSC were injected and were found to significantly reduce the M1 phenotype in macrophages, decrease IL-1 $\beta$ (Interleukin-1 $\beta$ ) and IL-6 expression, increase IL-10 expression, and were able to increase alternate monocyte/macrophage activation, thus MSC may function to repair the myocardium through IL-10mediated infiltration of pro-inflammatory macrophages to anti-inflammatory macrophages at the site of infarction(90). Some studies have shown that mesenchymal stem cells not only act directly on the infarcted myocardium, but also migrate to the spleen, liver, bone marrow and other organs, and regulate the polarization of macrophages through their paracrine function, promoting the transformation of macrophages in the infarcted myocardium towards the M2 phenotype or the transformation of proinflammatory cells from M1 type to anti-inflammatory cells from M2 type in organs other than the heart, thus regulating the inflammation of myocardial infarction(91, 92). MSC were injected in a porcine model of heart failure combined with myocardial infarction (MI) and rapid pacing and were found to exhibit enhanced viability and promote vascular regeneration by activating regulatory $T$ cells and reducing inflammatory cells(93).

\section{Heart failure}

Heart failure is a progressive disease, a syndrome that occurs when cardiovascular disease progresses to a more severe stage. It is usually caused by structural and functional changes in the myocardium due to organic or functional lesions of the heart, and a decrease in the collapse capacity of the ventricles, which impairs the filling degree and ejection fraction capacity of the ventricles. And immune activation and inflammatory responses play an important role in the course of heart failure.

Mesenchymal stem cells can be an effective treatment for heart failure through immunomodulation. Isolation of peripheral blood mononuclear cells from fresh whole blood samples from healthy normal subjects or patients with end-stage heart failure, followed by co-culture with MSC-derived exosomes, showed that MSCs were highly inhibitory, inhibiting lymphocyte proliferation and antibody production in vitro, and that IgG3 production was high in plasma cells from patients with end-stage heart failure and was shown to be inhibited by MSCs in an in vitro assay(94). CD4 is normally expressed on the surface of 
human T lymphocytes, while Th1 cells in CD4 have a role in humoral immunity(95). CD4/CD8 is an important indicator of immune regulation(96). Co-transplantation of MSCs into mice with pluripotent stem cell-derived cardiomyocytes revealed that MSCs affect activated lymphocytes directly through cellto-cell contact, thereby reducing the CD8/CD4 ratio, the proportion of Th1-positive cells among CD4positive cells, and the secretion of several inflammation-associated cytokines. And through this pathway, it has a therapeutic effect on severe heart failure(97).

post-infarction myocardial fibrosis and poor ventricular remodeling as major causes of heart failure(98). Ischemic and non-ischemic injuries to the heart cause detrimental changes in the size, shape and function of the ventricles, and this detrimental remodeling is mediated by neurohormonal and hemodynamic changes that can lead to heart failure and even death in severe cases(99). In a porcine model of anterior wall myocardial infarction, MSCs were injected and found to be immunoprotective and to reduce adverse remodeling after myocardial infarction(100). In contrast, in a mouse model of inflammatory DCM(Dilated cardiomyopathy), MSC inhibited poor cardiac remodeling, improved organ function, and prolonged lifespan(101). While myocardial fibrosis often causes left ventricular dysfunction, which can lead to heart failure(102). In a rat model of myocardial infarction, MSC were taken from homozygous rats and found to significantly inhibit the proliferation of lymphocytes and reduce the degree of myocardial fibrosis to treat heart failure(103).

\section{Atherosclerosis}

Atherosclerosis is a major cause of cardiovascular disease, which is a chronic vascular inflammatory disease. Atherosclerotic lesions contain macrophages, T-cells, and other immune response cells, and their development is importantly linked to immune regulation(104). Because of their immunomodulatory and tissue regenerative capabilities, MSCs are well positioned to treat atherosclerosis. TGF- $\beta 1$ can mount an immune response when activated, and regulatory $T$ cells can suppress proximal immune cells by activating GARP(Glycoprotein -A repetitions predominant) -mediated activation of potential TGF- $\beta 1$ acting on their surface with integrin aV $\beta 8$. Treatment of atherosclerotic mice with MSCs revealed increased secretion of anti-inflammatory cytokines such as TGF- $\beta 1$ and IL-10 and decreased secretion of proinflammatory cytokines such as TNF- $\alpha$, IL-1 $\beta$ and IL-6, and allowed TGF- $\beta 1$ to participate in MSCmediated induction of CD4+CD25+Foxp3(Forkhead box P3)+ regulatory $T$ cells and NK cells Decrease in proliferation $(105,106)$. While MSCs can exert immunomodulatory and immunosuppressive effects through the secretion of humoral factors, culture media for adipose-derived MSCs, like MSCs, can reduce the expression of cell adhesion factors by inhibiting the mitogen-activated protein kinase (MAPK) and NFKB pathways and also reduce the accumulation of macrophages in the vessel wall by inhibiting MAPK and NFKB pathways. The кB pathway decreases the lipopolysaccharide-induced increase in M1 marker expression and increases M2 marker expression by activating the STAT3(Signal transduction and activation protein 3 )signaling pathway(107). The polarization of macrophages is closely related to atherosclerosis. Abnormal lipid metabolism can lead to endothelial dysfunction and the secretion of adhesion factors, which can lead to the recruitment of macrophages to form foam cells, thus promoting the formation of atherosclerotic plaque. Macrophages secrete anti-inflammatory factors, such as IL-10, 
TGF- $\beta$, and can promote blood vessel regeneration and tissue remodeling and repair(108). IL- 6 is produced in response to infection and tissue injury and contributes to host defense by stimulating the acute phase response, hematopoiesis, and immune response. However, persistent dysregulation of IL-6 synthesis plays a pathological role in chronic inflammation and autoimmunity(109). MSC significantly suppressed the pronounced systemic IL- 6 response induced by intranasal administration of LPS in LPSinduced APOE(Apolipoprotein E)*3-Leiden mice models of acute and chronic inflammation, emphysema, and atherosclerosis(110). Human induced pluripotent stem cells(iPSC-MSCs) were administered intravenously to APOE knockout mice on a HFD(High-fat diet) for 12 weeks, and iPSC-MSCs were found to significantly reduce plaque size. and made the macrophages in the plaques lower than those in the controls. In addition, iPSC-MSCs reduced inflammation by reducing serum levels of inflammatory cytokines, such as TNF-a and IL-6, thereby treating atherosclerosis(111).

\section{Myocardial Ischemia Reperfusion Injury}

After myocardial infarction, timely reperfusion treatment can reduce the infarct area, but after reperfusion treatment, arrhythmia, myocardial contraction dysfunction and other symptoms often appear, which is myocardial ischemia-reperfusion injury(112). Infiltration of inflammatory cells occurs after myocardial ischemia/reperfusion, allowing the progression of myocardial ischemia/reperfusion injury toward inflammatory injury. In a mouse model of acute myocardial infarction, mesenchymal stem cell-derived exosomes were found to exert profound immunomodulatory effects on dendritic cells, dendritic cells, and monocytes or macrophages, and high expression of miRNA-181 mesenchymal stem cell-derived exosomes could create an anti-inflammatory environment, enhance Treg cell polarization, and significantly ameliorate ischemia-reperfusion through downstream c-Fos protein Cardiac function and infarct size in perfusion-impaired mice(113). TLR2, the most widely expressed member of the TLR family, is a type I transmembrane protein that acts as a pattern recognition receptor, recognizes and binds to several pathogen-associated molecular patterns PAPS and triggers a cascade of signaling that leads to the release of mediators of inflammation, thereby initiating an innate immune response. TLR2(Toll-like receptor 2) is associated with inflammation and myocardial dysfunction after ischemia/reperfusion injury (I/R), and knockdown of mesenchymal stem cell-derived exosomes of TLR2 improves myocardial recovery from immunomodulation and promotes the release of vascular growth factor, thereby protecting cardiac function(114). STAT3 can be activated by stimuli such as many cytokines or growth factors and plays a role in inducing the transcription of target genes in response to the release of IL6 during inflammation(115). STAT3 also modulates cardiomyocyte apoptosis and cell proliferation immunomodulation after ischemia/reperfusion .In a rat model of myocardial ischemia/reperfusion, intracoronary infusion of MSCs was found to improve postoperative left ventricular function, reduce tumor necrosis factor secretion, and modulate the immune response of cardiomyocytes via STAT3 as a mediator(116).

\section{Cardiomyopathy and myocarditis}


Dilated cardiomyopathy can occur when there is some genetic or environmental damage to the heart muscle. Dilated cardiomyopathy refers to left ventricular dilation and systolic dysfunction in the absence of coronary artery disease or abnormal loading conditions in proportion to the degree of damage, and it is one of the causes of heart failure(117). MSCs can secrete cytokines such as HGF and VEGF. After MSCs were injected into the myocardium, they were found to increase myocardial capillary density, decrease left ventricular end-diastolic pressure, increase left ventricular maximal isovolumic systolic index (dP/dt), and improve left ventricular systolic function(118). Chronic Chagas disease cardiomyopathy, an extremely fatal inflammatory cardiomyopathy associated with the patient's own innate immune response, can be characterized by abundant expression of pro-inflammatory cytokine Th1 T cells, cardiomyocyte hypertrophy, and prominent fibrosis in the area of the heart lesion(119). Researchers transplanted MSCs into Chronic Chagas disease cardiomyopathy mice and found that MSCs caused inhibition of cardiac inflammation and fibrosis and reduced the expression levels of CD45, TNFa, IL-1 $\beta$, IL-6, and IFN $\gamma$, suggesting that MSCs have rich potential for the treatment of Chronic Chagas disease cardiomyopathy(120).

Myocarditis is an inflammatory disease of the myocardium associated with immune dysfunction that, if left untreated, is likely to result in cardiogenic shock and death(121). Researchers injected autologous bone marrow or allogenic placental membrane-derived mesenchymal stem cells (FM-MSCs) into experimental immune myocarditis mice and found that FM-MSC-treated experimental immune myocarditis mice had significantly fewer infiltrating Th17 cells and a significantly lower percentage of Th1 cells, suggesting that FM-MSCs can improve Th1/Th17 immunity by suppressing Th1/Th17 immunity. Experimental immune myocarditis(122). In addition, MSCs can also reduce the severity of experimental immune myocarditis by releasing hepatocyte growth factors and inhibiting the expression of IL-2, IL-6, and IL-10 in the myocardium(123). CVB3(Coxsackievirus B3) can induce myocarditis, an immune-mediated disease. Co-culture of MSCs with CVB3-infected $\mathrm{HL}-1$ cardiomyocytes revealed that CVB3-induced CD4- and CD8-T cell activation of HL-1 cells could be reduced by MSCs in a nitric oxide (NO)-dependent manner. In addition, MSCs require priming by IFN-y to exert their protective effects(124).

Table.2 Differences in the efficacy of mesenchymal stem cells in different cardiovascular diseases 


\begin{tabular}{|c|c|c|c|}
\hline Type of disease & Involved immune cells & Involved cytokines & $\begin{array}{l}\text { Signaling pathways } \\
\text { involved }\end{array}$ \\
\hline $\begin{array}{l}\text { Myocardial } \\
\text { infarction }\end{array}$ & $\begin{array}{l}\text { Mast cells, regulatory T } \\
\text { cells, NK cells, neutrophils, } \\
\text { macrophages }(88)\end{array}$ & $\begin{array}{l}\text { IDO, COX2, PGE2, } \\
\text { TNF-a, IL-1 } \beta \text {, IL-6, IL- } \\
10, \text { IL-33(89)(91) }\end{array}$ & $\begin{array}{l}\text { Wnt-singaling, NFKB- } \\
\text { singaling(92) }\end{array}$ \\
\hline Heart failure & $\begin{array}{l}\text { Helper T cells, B } \\
\text { lymphocytes(96)(99) }\end{array}$ & IL-2, TGF- $\beta(96)$ & PD1 signalling(96) \\
\hline \multirow[t]{2}{*}{ Atherosclerosis } & $\begin{array}{l}\text { Regulatory T-cells, } \\
\text { Macrophages }\end{array}$ & \multirow[t]{2}{*}{$\begin{array}{l}\text { TNF-a, IL-6, IL-12, IL- } \\
10, \text { IL-1R(107,108) }\end{array}$} & \multirow[t]{2}{*}{$\begin{array}{l}\text { MAPK singaling, NFKB- } \\
\text { singaling(109) }\end{array}$} \\
\hline & $(107,108,109)$ & & \\
\hline \multirow{2}{*}{$\begin{array}{l}\text { Myocardia- } \\
\text { Ischemia } \\
\text { Reperfusion- } \\
\text { injury }\end{array}$} & Dendritic cells, Monocytes, & \multirow[t]{2}{*}{ TNF, IL-6(117,118) } & STAT3singaling, \\
\hline & Macrophages(115) & & PI3K/AKTsingaling(118) \\
\hline Cardiomyopathy & Helper T cells (121) & $\begin{array}{l}\text { HGF, VEGF, TNFa, IL- } \\
1 \beta, \text { IL-6, IFNY(120) } \\
(122)\end{array}$ & Gal-3 singaling(122) \\
\hline Myocarditis & Helper T cells(124) & $\begin{array}{l}\text { IL-2, IL-6, IL-10, IFN- } \\
\mathrm{Y}(125,126)\end{array}$ & PKC singaling(125) \\
\hline
\end{tabular}

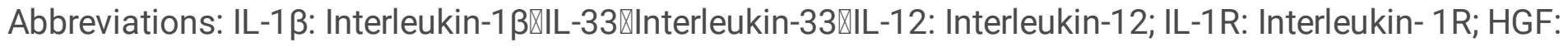
Hepatocyte growth factor ; VEGF: Vascular endothelial growth factor; IFN $\gamma$ : Interferon $\gamma$, IDO: Indoleamine 2,3-dioxygenase, PD-1: Programmed death-1, Wnt: Wingless/Integrated, MAPK: MitogenActivated Protein Kinase, Gal-3:Galectin-3, PKC: Protein kinase C.

\section{Conclusion}

Mesenchymal stem cells are pluripotent stem cells with self-renewal capacity and multidirectional differentiation. They represent the most promising direction for the treatment of diseases such as inflammatory, neurological, cardiovascular, and autoimmune diseases because of their multilineage differentiation potential, immunomodulatory properties, and pro-angiogenic properties(126). Also, its secreted product, exosomes, play an important role in functions such as multidirectional differentiation. MSCs have potent immunomodulatory and anti-inflammatory activities, which are mediated by their paracrine function, contributing to anti-inflammatory and tissue repair(127). Therefore, it has remarkable efficacy in the treatment of cardiovascular diseases. For example, MSCs mediate cardiomyocyte immune responses through STAT3 to improve myocardial ischemia-reperfusion injury; exosomes significantly improve cardiac function in mice with ischemia-reperfusion injury by regulating c-Fos protein and enhancing Treg cell polarization; MSCs reduce the inflammatory response in the myocardial infarction zone by increasing IL-10 levels; MSCs can be used to treat atherosclerosis by modulating the phenotypic transition between the pro-inflammatory and anti-inflammatory phenotypes of macrophages. However, during clinical trials, some problems still occur, such as unintended differentiation of MSCs, decreased in 
vivo survival of transplanted MSCs, and calcification in the infarcted area was also observed in clinical trials for the long-term efficacy of MSCs in the treatment of myocardial infarction[126]. Storage and transport of MSCs has also become an issue for clinical use, and studies have shown that cryopreservation of MSCs can lead to impairment of their immunomodulatory properties(128).Therefore, although the use of MSCs immunomodulatory function for cardiovascular disease treatment may be a breakthrough and promising therapeutic approach, most MSC treatments are still in the state of preclinical technology and further basic research and clinical trials are needed to ensure that MSCs will play a more important role in the future of cardiovascular therapy.

\section{Abbreviations}

ALI: Acute lung injury

APOE: Apolipoprotein E

BAFF:B-cell activating factor

BCR:B-cell receptor

BMSC :Bone marrow mesenchymal stem cells

CCR5:CC chemokine receptor 5

CCL2:Chemokine C-C motif ligand 2

CCL5: Chemokine C-C motif ligand 5

CCL19:Chemokine C-C motif ligand19

Con A :Concanavalin A

COX2:Cyclooxygenase 2

CVB3:Coxsackievirus B3

CXCR3: CXC chemokine receptor 3

CXCR9:CXC chemokine ligand 9

CXCR10:CXC chemokine ligand 10

CXCR11: CXC chemokine ligand 11

DCM: Dilated cardiomyopathy

DCs: Dendritic cells 
EAE: Encephalomyelitis

EP2:Prostaglandin E Receptor 2

EP4: Prostaglandin E Receptor 4

FEV1:Forced Expiratory Volume in the first second

Foxp3:Forkhead box P3

Fox01:Forkhead box transcription factor 01

Gal-3:Galectin-3

GARP: Glycoprotein -A repetitions predominant

H3K27me3:Trimethylatin $\mathrm{f}$ iysine $27 \mathrm{n}$ histne 3

HFD: High-fat diet

HGF :Hepatocyte growth factor

IDO: Indoleamine 2,3-dioxygenase

IEC :Immunosuppressive towards effector cells

IFN $y$ :Interferon $Y$

IGF-1:Insulin-like growth factor-1

IL-6 :Interleukin-6

IL-10:Interleukin-10

IL-1 $\beta$ :Interleukin-1 $\beta$

IL-33: Interleukin-33

Im DCs: Immature dendritic cells

INOS :Inducible nitric oxide synthase

LPS: Lipopolysaccharide

MAPK: Mitogen-Activated Protein Kinase

mDC: Mature dendritic cells 


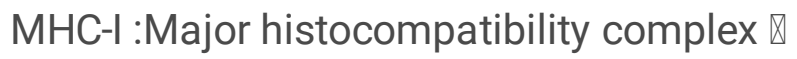

MHC-II :Major histocompatibility complex II

MSCs: Mesenchymal stem cells

NCR: the Natural cytotoxic receptor

NFKB: Nuclear factor kappa-B

NLRP3 :Recombinant NLR Family, Pyrin Domain Containing Protein 3

OVA: Ovalbumin

Pax5: Paired-box 5

PD-1: Programmed death-1

PD-L1 :Programmed cell death 1 ligand 1

PKC: Protein kinase $C$

PGE2: Prostaglandin E2

rDC: Regulatory dendritic cell

STAT3:Signal transduction and activation protein 3

TGF- $\beta$ :Transforming growth factor Beta

TNF-a:Tumor necrosis factor Alpha

TRL2:Toll-like receptor 2

TRL3: Toll-like receptor 3

TRL4:Toll-like receptor 4

VEGF: Vascular endothelial growth factor

XBP1:X-box binding protein 1

Wnt: Wingless/Integrated

\section{Declarations}

\section{Acknowlendgments}


We thank all the members of the Zhang laboratory for their help and constructive discussions.

\section{Authors' contributions}

YW and ZQ analyzed the current literature and wrote the manuscript. $Z Y, N J, X Y$ and $D G$ wrote and revised the manuscript. JZ and $M L$ designed the manuscript. All authors read and approved the final manuscript.

\section{Funding}

This study was supported by the National Natural Science Foundation of China(Grant No.81804046).

\section{Availability of data and materials}

Not applicable.

\section{Ethics approval and consent to participate}

Not applicable.

\section{Consent for publication}

Not applicable.

\section{Competing interests}

Not applicable.

\section{Contributor Information}

Yueyao Wang, E-mail: wyy98992020@163.com

Zhongwen Qi, E-mail: 13820596855@163.com

Zhipeng Yan, E-mail: jxy2591797849@163.com

Nan Ji, E-mail: jinan935@163.com

XiaoYa Yang, E-mail: yangxy9518@163.com

Dongjie Gao, E-mail: gaodongjie96@163.com

Junping Zhang, E-mail: tjzhtcm@163.com

Meng LI, E-mail: zhongyilimeng@163.com

\section{References}


1. Ding DC, Shyu WC, Lin SZ. Mesenchymal stem cells. Cell transplantation. 2011;20(1):5-14.

2. Harrell CR, Jovicic N, Djonov V, Arsenijevic N, Volarevic V. Mesenchymal Stem Cell-Derived Exosomes and Other Extracellular Vesicles as New Remedies in the Therapy of Inflammatory Diseases. Cells. 2019;8(12).

3. Wang Z, Zhao Y. Gut microbiota derived metabolites in cardiovascular health and disease. Protein \& cell. 2018;9(5):416-31.

4. Albany CJ, Trevelin SC, Giganti G, Lombardi G, Scottà C. Getting to the Heart of the Matter: The Role of Regulatory T-Cells (Tregs) in Cardiovascular Disease (CVD) and Atherosclerosis. Frontiers in immunology. 2019;10:2795.

5. Liu Z, Mikrani R, Zubair HM, Taleb A, Naveed M, Baig M, et al. Systemic and local delivery of mesenchymal stem cells for heart renovation: Challenges and innovations. European journal of pharmacology. 2020;876:173049.

6. Uccelli A, Moretta L, Pistoia V. Mesenchymal stem cells in health and disease. Nature reviews Immunology. 2008;8(9):726-36.

7. Spees JL, Lee RH, Gregory CA. Mechanisms of mesenchymal stem/stromal cell function. Stem cell research \& therapy. 2016;7(1):125.

8. Samsonraj RM, Raghunath M, Nurcombe V, Hui JH, van Wijnen AJ, Cool SM. Concise Review: Multifaceted Characterization of Human Mesenchymal Stem Cells for Use in Regenerative Medicine. Stem cells translational medicine. 2017;6(12):2173-85.

9. Li T, Xia M, Gao Y, Chen Y, Xu Y. Human umbilical cord mesenchymal stem cells: an overview of their potential in cell-based therapy. Expert opinion on biological therapy. 2015;15(9):1293-306.

10. He H, Liu X, Peng L, Gao Z, Ye Y, Su Y, et al. Promotion of hepatic differentiation of bone marrow mesenchymal stem cells on decellularized cell-deposited extracellular matrix. BioMed research international. 2013;2013:406871.

11. Lavrentieva A, Hatlapatka T, Neumann A, Weyand B, Kasper C. Potential for osteogenic and chondrogenic differentiation of MSC. Advances in biochemical engineering/biotechnology. 2013;129:73-88.

12. Feng N, Han Q, Li J, Wang S, Li H, Yao X, et al. Generation of highly purified neural stem cells from human adipose-derived mesenchymal stem cells by Sox1 activation. Stem cells and development. 2014;23(5):515-29.

13. J MP, Debabrata B. Activation and Differentiation of Mesenchymal Stem Cells. \%J Methods in molecular biology (Clifton, N.J.). 2017;1554.

14. Wang S, Zhu R, Li H, Li J, Han Q, Zhao RC. Mesenchymal stem cells and immune disorders: from basic science to clinical transition. Frontiers of medicine. 2019;13(2):138-51.

15. Lopatina T, Kalinina N, Karagyaur M, Stambolsky D, Rubina K, Revischin A, et al. Correction: AdiposeDerived Stem Cells Stimulate Regeneration of Peripheral Nerves: BDNF Secreted by These Cells Promotes Nerve Healing and Axon Growth De Novo. PloS one. 2019;14(7):e0219946. 
16. Lee Y, El Andaloussi S, Wood MJ. Exosomes and microvesicles: extracellular vesicles for genetic information transfer and gene therapy. Human molecular genetics. 2012;21(R1):R125-34.

17. Shi Y, Wang Y, Li Q, Liu K, Hou J, Shao C, et al. Immunoregulatory mechanisms of mesenchymal stem and stromal cells in inflammatory diseases. Nature reviews Nephrology. 2018;14(8):493-507.

18. Spaggiari GM, Capobianco A, Becchetti S, Mingari MC, Moretta L. Mesenchymal stem cell-natural killer cell interactions: evidence that activated NK cells are capable of killing MSCs, whereas MSCs can inhibit IL-2-induced NK-cell proliferation. Blood. 2006;107(4):1484-90.

19. Qin Y, Zhou Z, Zhang F, Wang Y, Shen B, Liu Y, et al. Induction of Regulatory B-Cells by Mesenchymal Stem Cells is Affected by SDF-1a-CXCR7. Cellular physiology and biochemistry : international journal of experimental cellular physiology, biochemistry, and pharmacology. 2015;37(1):117-30.

20. Consentius C, Akyüz L, Schmidt-Lucke JA, Tschöpe C, Pinzur L, Ofir R, et al. Mesenchymal Stromal Cells Prevent Allostimulation In Vivo and Control Checkpoints of Th1 Priming: Migration of Human DC to Lymph Nodes and NK Cell Activation. Stem cells (Dayton, Ohio). 2015;33(10):3087-99.

21. Gupte KS, Vanikar AV, Trivedi HL, Patel CN, Patel JV. In-vitro generation of interleukin-10 secreting Bregulatory cells from donor adipose tissue derived mesenchymal stem cells and recipient peripheral blood mononuclear cells for potential cell therapy. Biomedical journal. 2017;40(1):49-54.

22. Spaggiari GM, Abdelrazik H, Becchetti F, Moretta L. MSCs inhibit monocyte-derived DC maturation and function by selectively interfering with the generation of immature DCs: central role of MSCderived prostaglandin E2. Blood. 2009;113(26):6576-83.

23. Yang FY, Chen R, Zhang X, Huang B, Tsang LL, Li X, et al. Preconditioning Enhances the Therapeutic Effects of Mesenchymal Stem Cells on Colitis Through PGE2-Mediated T-Cell Modulation. Cell transplantation. 2018;27(9):1352-67.

24. Jin L, Deng Z, Zhang J, Yang C, Liu J, Han W, et al. Mesenchymal stem cells promote type 2 macrophage polarization to ameliorate the myocardial injury caused by diabetic cardiomyopathy. Journal of translational medicine. 2019;17(1):251.

25. De Miguel MP, Fuentes-Julián S, Blázquez-Martínez A, Pascual CY, Aller MA, Arias J, et al. Immunosuppressive properties of mesenchymal stem cells: advances and applications. Current molecular medicine. 2012;12(5):574-91.

26. Muñoz-Fernández R, Prados A, Leno-Durán E, Blázquez A, García-Fernández JR, Ortiz-Ferrón G, et al. Human decidual stromal cells secrete $C-X-C$ motif chemokine 13 , express $B$ cell-activating factor and rescue $B$ lymphocytes from apoptosis: distinctive characteristics of follicular dendritic cells. Human reproduction (Oxford, England). 2012;27(9):2775-84.

27. Wilke CM, Kryczek I, Zou W. Antigen-presenting cell (APC) subsets in ovarian cancer. International reviews of immunology. 2011;30(2-3):120-6.

28. Saiz ML, Rocha-Perugini V, Sánchez-Madrid F. Tetraspanins as Organizers of Antigen-Presenting Cell Function. Frontiers in immunology. 2018;9:1074.

29. Koelwyn GJ, Corr EM, Erbay E, Moore KJ. Regulation of macrophage immunometabolism in atherosclerosis. Nature immunology. 2018;19(6):526-37. 
30. Wynn TA, Chawla A, Pollard JW. Macrophage biology in development, homeostasis and disease. Nature. 2013;496(7446):445-55.

31. Wang YC, Ma HD, Yin XY, Wang YH, Liu QZ, Yang JB, et al. Forkhead Box 01 Regulates Macrophage Polarization Following Staphylococcus aureus Infection: Experimental Murine Data and Review of the Literature. Clinical reviews in allergy \& immunology. 2016;51(3):353-69.

32. Feng $Y, X u Q$, Yang $Y$, Shi W, Meng W, Zhang $H$, et al. The therapeutic effects of bone marrow-derived mesenchymal stromal cells in the acute lung injury induced by sulfur mustard. Stem cell research \& therapy. 2019;10(1):90.

33. Xu R, Zhang F, Chai R, Zhou W, Hu M, Liu B, et al. Exosomes derived from pro-inflammatory bone marrow-derived mesenchymal stem cells reduce inflammation and myocardial injury via mediating macrophage polarization. Journal of cellular and molecular medicine. 2019;23(11):7617-31.

34. Fan B, Li C, Szalad A, Wang L, Pan W, Zhang R, et al. Mesenchymal stromal cell-derived exosomes ameliorate peripheral neuropathy in a mouse model of diabetes. Diabetologia. 2020;63(2):431-43.

35. Liu F, Qiu H, Xue M, Zhang S, Zhang X, Xu J, et al. MSC-secreted TGF- $\beta$ regulates lipopolysaccharidestimulated macrophage M2-like polarization via the Akt/Fox01 pathway. Stem cell research \& therapy. 2019;10(1):345.

36. Pajarinen J, Lin T, Gibon E, Kohno Y, Maruyama M, Nathan K, et al. Mesenchymal stem cellmacrophage crosstalk and bone healing. Biomaterials. 2019;196:80-9.

37. Giri J, Das R, Nylen E, Chinnadurai R, Galipeau J. CCL2 and CXCL12 Derived from Mesenchymal Stromal Cells Cooperatively Polarize IL-10+ Tissue Macrophages to Mitigate Gut Injury. Cell reports. 2020;30(6):1923-34.e4.

38. Li C, Jin Y, Wei S, Sun Y, Jiang L, Zhu Q, et al. Hippo Signaling Controls NLR Family Pyrin Domain Containing 3 Activation and Governs Immunoregulation of Mesenchymal Stem Cells in Mouse Liver Injury. Hepatology (Baltimore, Md). 2019;70(5):1714-31.

39. Lu X, Ru Y, Chu C, Lv Y, Gao Y, Jia Z, et al. Lentivirus-mediated IL-10-expressing Bone Marrow Mesenchymal Stem Cells promote corneal allograft survival via upregulating IncRNA 003946 in a rat model of corneal allograft rejection. Theranostics. 2020;10(18):8446-67.

40. Macri C, Pang ES, Patton T, O'Keeffe M. Dendritic cell subsets. Seminars in cell \& developmental biology. 2018;84:11-21.

41. Lee YS, Radford KJ. The role of dendritic cells in cancer. International review of cell and molecular biology. 2019;348:123-78.

42. Puhr S, Lee J, Zvezdova E, Zhou YJ, Liu K. Dendritic cell development-History, advances, and open questions. Seminars in immunology. 2015;27(6):388-96.

43. Collin M, Bigley V. Human dendritic cell subsets: an update. Immunology. 2018;154(1):3-20.

44. Lu Z, Chang W, Meng S, Xu X, Xie J, Guo F, et al. Mesenchymal stem cells induce dendritic cell immune tolerance via paracrine hepatocyte growth factor to alleviate acute lung injury. Stem cell research \& therapy. 2019;10(1):372. 
45. Clark GJ, Silveira PA, Hogarth PM, Hart DNJ. The cell surface phenotype of human dendritic cells. Seminars in cell \& developmental biology. 2019;86:3-14.

46. English K, Barry FP, Mahon BP. Murine mesenchymal stem cells suppress dendritic cell migration, maturation and antigen presentation. Immunology letters. 2008;115(1):50-8.

47. Scutera S, Salvi V, Lorenzi L, Piersigilli G, Lonardi S, Alotto D, et al. Adaptive Regulation of Osteopontin Production by Dendritic Cells Through the Bidirectional Interaction With Mesenchymal Stromal Cells. Frontiers in immunology. 2018;9:1207.

48. Favaro E, Carpanetto A, Caorsi C, Giovarelli M, Angelini C, Cavallo-Perin P, et al. Human mesenchymal stem cells and derived extracellular vesicles induce regulatory dendritic cells in type 1 diabetic patients. Diabetologia. 2016;59(2):325-33.

49. Briseño CG, Murphy TL, Murphy KM. Complementary diversification of dendritic cells and innate lymphoid cells. Current opinion in immunology. 2014;29:69-78.

50. Jo H, Eom YW, Kim HS, Park HJ, Kim HM, Cho MY. Regulatory Dendritic Cells Induced by Mesenchymal Stem Cells Ameliorate Dextran Sodium Sulfate-Induced Chronic Colitis in Mice. Gut and liver. 2018;12(6):664-73.

51. Shahir M, Mahmoud Hashemi S, Asadirad A, Varahram M, Kazempour-Dizaji M, Folkerts G, et al. Effect of mesenchymal stem cell-derived exosomes on the induction of mouse tolerogenic dendritic cells. Journal of cellular physiology. 2020;235(10):7043-55.

52. Kumar BV, Connors TJ, Farber DL. Human T Cell Development, Localization, and Function throughout Life. Immunity. 2018;48(2):202-13.

53. Lee GR. The Balance of Th17 versus Treg Cells in Autoimmunity. International journal of molecular sciences. 2018;19(3).

54. Di Nicola M, Carlo-Stella C, Magni M, Milanesi M, Longoni PD, Matteucci P, et al. Human bone marrow stromal cells suppress T-lymphocyte proliferation induced by cellular or nonspecific mitogenic stimuli. Blood. 2002;99(10):3838-43.

55. Goodwin M, Sueblinvong V, Eisenhauer P, Ziats NP, LeClair L, Poynter ME, et al. Bone marrow-derived mesenchymal stromal cells inhibit Th2-mediated allergic airways inflammation in mice. Stem cells (Dayton, Ohio). 2011;29(7):1137-48.

56. Chen Q, Duan X, Xu M, Fan H, Dong Y, Wu H, et al. BMSC-EVs regulate Th17 cell differentiation in UC via H3K27me3. Molecular immunology. 2020;118:191-200.

57. Zhou C, Wu XR, Liu HS, Liu XH, Liu GH, Zheng XB, et al. Immunomodulatory Effect of Urine-derived Stem Cells on Inflammatory Bowel Diseases via Downregulating Th1/Th17 Immune Responses in a PGE2-dependent Manner. Journal of Crohn's \& colitis. 2020;14(5):654-68.

58. Ohue Y, Nishikawa H. Regulatory T (Treg) cells in cancer: Can Treg cells be a new therapeutic target? Cancer science. 2019;110(7):2080-9.

59. Wing JB, Tanaka A, Sakaguchi S. Human FOXP3(+) Regulatory T Cell Heterogeneity and Function in Autoimmunity and Cancer. Immunity. 2019;50(2):302-16. 
60. Zhang Q, Fu L, Liang Y, Guo Z, Wang L, Ma C, et al. Exosomes originating from MSCs stimulated with TGF- $\beta$ and IFN- $\gamma$ promote Treg differentiation. Journal of cellular physiology. 2018;233(9):6832-40.

61. Riazifar M, Mohammadi MR, Pone EJ, Yeri A, Lässer C, Segaliny Al, et al. Stem Cell-Derived Exosomes as Nanotherapeutics for Autoimmune and Neurodegenerative Disorders. ACS nano. 2019;13(6):6670-88.

62. Rashedi I, Gómez-Aristizábal A, Wang XH, Viswanathan S, Keating A. TLR3 or TLR4 Activation Enhances Mesenchymal Stromal Cell-Mediated Treg Induction via Notch Signaling. Stem cells (Dayton, Ohio). 2017;35(1):265-75.

63. Mauri C, Bosma A. Immune regulatory function of B cells. Annual review of immunology. 2012;30:221-41.

64. Zhang Q, lida R, Shimazu T, Kincade PW. Replenishing B lymphocytes in health and disease. Current opinion in immunology. 2012;24(2):196-203.

65. Rawlings DJ, Metzler G, Wray-Dutra M, Jackson SW. Altered B cell signalling in autoimmunity. Nature reviews Immunology. 2017;17(7):421-36.

66. LeBien TW, Tedder TF. B lymphocytes: how they develop and function. Blood. 2008;112(5):1570-80.

67. Tolar P. Cytoskeletal control of B cell responses to antigens. Nature reviews Immunology. 2017;17(10):621-34.

68. Di Trapani M, Bassi G, Midolo M, Gatti A, Kamga PT, Cassaro A, et al. Differential and transferable modulatory effects of mesenchymal stromal cell-derived extracellular vesicles on $\mathrm{T}, \mathrm{B}$ and NK cell functions. Scientific reports. 2016;6:24120.

69. Chen X, Cai C, Xu D, Liu Q, Zheng S, Liu L, et al. Human Mesenchymal Stem Cell-Treated Regulatory CD23(+)CD43(+) B Cells Alleviate Intestinal Inflammation. Theranostics. 2019;9(16):4633-47.

70. Peng Y, Chen X, Liu Q, Xu D, Zheng H, Liu L, et al. Alteration of naïve and memory B-cell subset in chronic graft-versus-host disease patients after treatment with mesenchymal stromal cells. Stem cells translational medicine. 2014;3(9):1023-31.

71. Chen S, Zhao K, Lin R, Wang S, Fan Z, Huang F, et al. The efficacy of mesenchymal stem cells in bronchiolitis obliterans syndrome after allogeneic HSCT: A multicenter prospective cohort study. EBioMedicine. 2019;49:213-22.

72. Cunha C, Almeida CR, Almeida MI, Silva AM, Molinos M, Lamas S, et al. Systemic Delivery of Bone Marrow Mesenchymal Stem Cells for In Situ Intervertebral Disc Regeneration. Stem cells translational medicine. 2017;6(3):1029-39.

73. Starc N, Ingo D, Conforti A, Rossella V, Tomao L, Pitisci A, et al. Biological and functional characterization of bone marrow-derived mesenchymal stromal cells from patients affected by primary immunodeficiency. Scientific reports. 2017;7(1):8153.

74. Magatti M, Masserdotti A, Bonassi Signoroni P, Vertua E, Stefani FR, Silini AR, et al. B Lymphocytes as Targets of the Immunomodulatory Properties of Human Amniotic Mesenchymal Stromal Cells. Frontiers in immunology. 2020;11:1156. 
75. Wang X, Lazorchak AS, Song L, Li E, Zhang Z, Jiang B, et al. Immune modulatory mesenchymal stem cells derived from human embryonic stem cells through a trophoblast-like stage. Stem cells (Dayton, Ohio). 2016;34(2):380-91.

76. Morvan MG, Lanier LL. NK cells and cancer: you can teach innate cells new tricks. Nature reviews Cancer. 2016;16(1):7-19.

77. Hodgins JJ, Khan ST, Park MM, Auer RC, Ardolino M. Killers 2.0: NK cell therapies at the forefront of cancer control. The Journal of clinical investigation. 2019;129(9):3499-510.

78. Bradley T, Peppa D, Pedroza-Pacheco I, Li D, Cain DW, Henao R, et al. RAB11FIP5 Expression and Altered Natural Killer Cell Function Are Associated with Induction of HIV Broadly Neutralizing Antibody Responses. Cell. 2018;175(2):387-99.e17.

79. Mekhloufi A, Kosta A, Stabile H, Molfetta R, Zingoni A, Soriani A, et al. Bone Marrow Stromal CellDerived IL-8 Upregulates PVR Expression on Multiple Myeloma Cells via NF-kB Transcription Factor. Cancers. 2020;12(2).

80. Qingqing $M, X i n Z$, Meizhong S. Bone marrow mesenchymal stem cells altered the immunoregulatory activities of hepatic natural killer cells. Clinics and research in hepatology and gastroenterology. 2014;38(6):689-98.

81. Petri RM, Hackel A, Hahnel K, Dumitru CA, Bruderek K, Flohe SB, et al. Activated Tissue-Resident Mesenchymal Stromal Cells Regulate Natural Killer Cell Immune and Tissue-Regenerative Function. Stem cell reports. 2017;9(3):985-98.

82. Spaggiari GM, Capobianco A, Abdelrazik H, Becchetti F, Mingari MC, Moretta L. Mesenchymal stem cells inhibit natural killer-cell proliferation, cytotoxicity, and cytokine production: role of indoleamine 2,3-dioxygenase and prostaglandin E2. Blood. 2008;111(3):1327-33.

83. Ishida N, Ishiyama K, Saeki Y, Tanaka Y, Ohdan H. Cotransplantation of preactivated mesenchymal stem cells improves intraportal engraftment of islets by inhibiting liver natural killer cells in mice. American journal of transplantation : official journal of the American Society of Transplantation and the American Society of Transplant Surgeons. 2019;19(10):2732-45.

84. Almeida CR, Caires HR, Vasconcelos DP, Barbosa MA. NAP-2 Secreted by Human NK Cells Can Stimulate Mesenchymal Stem/Stromal Cell Recruitment. Stem cell reports. 2016;6(4):466-73.

85. Luger D, Lipinski MJ, Westman PC, Glover DK, Dimastromatteo J, Frias JC, et al. Intravenously Delivered Mesenchymal Stem Cells: Systemic Anti-Inflammatory Effects Improve Left Ventricular Dysfunction in Acute Myocardial Infarction and Ischemic Cardiomyopathy. Circulation research. 2017;120(10):1598-613.

86. Cayrol C, Girard JP. Interleukin-33 (IL-33): A nuclear cytokine from the IL-1 family. Immunological reviews. 2018;281(1):154-68.

87. Chen Y, Zuo J, Chen W, Yang Z, Zhang Y, Hua F, et al. The enhanced effect and underlying mechanisms of mesenchymal stem cells with IL-33 overexpression on myocardial infarction. Stem cell research \& therapy. 2019;10(1):295. 
88. Saraiva M, O'Garra A. The regulation of IL-10 production by immune cells. Nature reviews Immunology. 2010;10(3):170-81.

89. Meng X, Li J, Yu M, Yang J, Zheng M, Zhang J, et al. Transplantation of mesenchymal stem cells overexpressing IL10 attenuates cardiac impairments in rats with myocardial infarction. Journal of cellular physiology. 2018;233(1):587-95.

90. Dayan V, Yannarelli G, Billia F, Filomeno P, Wang XH, Davies JE, et al. Mesenchymal stromal cells mediate a switch to alternatively activated monocytes/macrophages after acute myocardial infarction. Basic research in cardiology. 2011;106(6):1299-310.

91. Peng Y, Pan W, Ou Y, Xu W, Kaelber S, Borlongan CV, et al. Extracardiac-Lodged Mesenchymal Stromal Cells Propel an Inflammatory Response Against Myocardial Infarction via Paracrine Effects. Cell transplantation. 2016;25(5):929-35.

92. Hotchkiss KM, Clark NM, Olivares-Navarrete R. Macrophage response to hydrophilic biomaterials regulates MSC recruitment and T-helper cell populations. Biomaterials. 2018;182:202-15.

93. Liao S, Zhang Y, Ting S, Zhen Z, Luo F, Zhu Z, et al. Potent immunomodulation and angiogenic effects of mesenchymal stem cells versus cardiomyocytes derived from pluripotent stem cells for treatment of heart failure. Stem cell research \& therapy. 2019;10(1):78.

94. van den Hoogen P, de Jager SCA, Mol EA, Schoneveld AS, Huibers MMH, Vink A, et al. Potential of mesenchymal- and cardiac progenitor cells for therapeutic targeting of B-cells and antibody responses in end-stage heart failure. PloS one. 2019;14(12):e0227283.

95. Loo TT, Gao Y, Lazarevic V. Transcriptional regulation of CD4(+) T(H) cells that mediate tissue inflammation. Journal of leukocyte biology. 2018;104(6):1069-85.

96. Overgaard NH, Jung JW, Steptoe RJ, Wells JW. CD4+/CD8+ double-positive T cells: more than just a developmental stage? Journal of leukocyte biology. 2015;97(1):31-8.

97. Yoshida S, Miyagawa S, Toyofuku T, Fukushima S, Kawamura T, Kawamura A, et al. Syngeneic Mesenchymal Stem Cells Reduce Immune Rejection After Induced Pluripotent Stem Cell-Derived Allogeneic Cardiomyocyte Transplantation. Scientific reports. 2020;10(1):4593.

98. Tallquist MD, Molkentin JD. Redefining the identity of cardiac fibroblasts. Nature reviews Cardiology. 2017;14(8):484-91.

99. Sekaran NK, Crowley AL, de Souza FR, Resende ES, Rao SV. The Role for Cardiovascular Remodeling in Cardiovascular Outcomes. Current atherosclerosis reports. 2017;19(5):23.

100. Johnston PV, Hwang CW, Bogdan V, Mills KJ, Eggan ER, Leszczynska A, et al. Intravascular Stem Cell Bioreactor for Prevention of Adverse Remodeling After Myocardial Infarction. Journal of the American Heart Association. 2019;8(15):e012351.

101. Martire A, Bedada FB, Uchida S, Pöling J, Krüger M, Warnecke H, et al. Mesenchymal stem cells attenuate inflammatory processes in the heart and lung via inhibition of TNF signaling. Basic research in cardiology. 2016;111(5):54.

102. González A, Schelbert EB, Díez J, Butler J. Myocardial Interstitial Fibrosis in Heart Failure: Biological and Translational Perspectives. Journal of the American College of Cardiology. 2018;71(15):1696- 
706.

103. Imanishi Y, Saito A, Komoda H, Kitagawa-Sakakida S, Miyagawa S, Kondoh H, et al. Allogenic mesenchymal stem cell transplantation has a therapeutic effect in acute myocardial infarction in rats. Journal of molecular and cellular cardiology. 2008;44(4):662-71.

104. Hansson GK, Hermansson A. The immune system in atherosclerosis. Nature immunology. 2011;12(3):204-12.

105. Li F, Guo X, Chen SY. Function and Therapeutic Potential of Mesenchymal Stem Cells in Atherosclerosis. Frontiers in cardiovascular medicine. 2017;4:32.

106. Liénart S, Merceron R, Vanderaa C, Lambert F, Colau D, Stockis J, et al. Structural basis of latent TGF$\beta 1$ presentation and activation by GARP on human regulatory T cells. Science (New York, NY). 2018;362(6417):952-6.

107. Takafuji Y, Hori M, Mizuno T, Harada-Shiba M. Humoral factors secreted from adipose tissue-derived mesenchymal stem cells ameliorate atherosclerosis in Ldlr-/- mice. Cardiovascular research. 2019;115(6):1041-51.

108. Adutler-Lieber S, Ben-Mordechai T, Naftali-Shani N, Asher E, Loberman D, Raanani E, et al. Human macrophage regulation via interaction with cardiac adipose tissue-derived mesenchymal stromal cells. Journal of cardiovascular pharmacology and therapeutics. 2013;18(1):78-86.

109. Tanaka T, Narazaki M, Kishimoto T. IL-6 in inflammation, immunity, and disease. Cold Spring Harbor perspectives in biology. 2014;6(10):a016295.

110. Khedoe P, de Kleijn S, van Oeveren-Rietdijk AM, Plomp JJ, de Boer HC, van Pel M, et al. Acute and chronic effects of treatment with mesenchymal stromal cells on LPS-induced pulmonary inflammation, emphysema and atherosclerosis development. PloS one. 2017;12(9):e0183741.

111. Shi H, Liang M, Chen W, Sun X, Wang X, Li C, et al. Human induced pluripotent stem cell-derived mesenchymal stem cells alleviate atherosclerosis by modulating inflammatory responses. Molecular medicine reports. 2018;17(1):1461-8.

112. Cohn JN, Ferrari R, Sharpe N. Cardiac remodeling-concepts and clinical implications: a consensus paper from an international forum on cardiac remodeling. Behalf of an International Forum on Cardiac Remodeling. Journal of the American College of Cardiology. 2000;35(3):569-82.

113. Wei Z, Qiao S, Zhao J, Liu Y, Li Q, Wei Z, et al. miRNA-181a over-expression in mesenchymal stem cell-derived exosomes influenced inflammatory response after myocardial ischemia-reperfusion injury. Life sciences. 2019;232:116632.

114. Ma SQ, Wei HL, Zhang X. TLR2 regulates allergic airway inflammation through NF-KB and MAPK signaling pathways in asthmatic mice. European review for medical and pharmacological sciences. 2018;22(10):3138-46.

115. Hillmer EJ, Zhang H, Li HS, Watowich SS. STAT3 signaling in immunity. Cytokine \& growth factor reviews. 2016;31:1-15.

116. Poynter JA, Herrmann JL, Manukyan MC, Wang Y, Abarbanell AM, Weil BR, et al. Intracoronary mesenchymal stem cells promote postischemic myocardial functional recovery, decrease 
inflammation, and reduce apoptosis via a signal transducer and activator of transcription 3 mechanism. Journal of the American College of Surgeons. 2011;213(2):253-60.

117. Japp AG, Gulati A, Cook SA, Cowie MR, Prasad SK. The Diagnosis and Evaluation of Dilated Cardiomyopathy. Journal of the American College of Cardiology. 2016;67(25):2996-3010.

118. Nagaya N, Kangawa K, Itoh T, Iwase T, Murakami S, Miyahara Y, et al. Transplantation of mesenchymal stem cells improves cardiac function in a rat model of dilated cardiomyopathy. Circulation. 2005;112(8):1128-35.

119. Cunha-Neto E, Chevillard C. Chagas disease cardiomyopathy: immunopathology and genetics. Mediators of inflammation. 2014;2014:683230.

120. Souza BSF, da Silva KN, Silva DN, Rocha VPC, Paredes BD, Azevedo CM, et al. Galectin-3 Knockdown Impairs Survival, Migration, and Immunomodulatory Actions of Mesenchymal Stromal Cells in a Mouse Model of Chagas Disease Cardiomyopathy. Stem cells international. 2017;2017:3282656.

121. Cooper LT, Jr. Myocarditis. The New England journal of medicine. 2009;360(15):1526-38.

122. Ohshima M, Yamahara K, Ishikane S, Harada K, Tsuda H, Otani K, et al. Systemic transplantation of allogenic fetal membrane-derived mesenchymal stem cells suppresses Th1 and Th17 T cell responses in experimental autoimmune myocarditis. Journal of molecular and cellular cardiology. 2012;53(3):420-8.

123. Okada H, Suzuki J, Futamatsu H, Maejima Y, Hirao K, Isobe M. Attenuation of autoimmune myocarditis in rats by mesenchymal stem cell transplantation through enhanced expression of hepatocyte growth factor. International heart journal. 2007;48(5):649-61.

124. Van Linthout S, Savvatis K, Miteva K, Peng J, Ringe J, Warstat K, et al. Mesenchymal stem cells improve murine acute coxsackievirus B3-induced myocarditis. European heart journal. 2011;32(17):2168-78.

125. Ellison-Hughes GM, Colley L, O'Brien KA, Roberts KA, Agbaedeng TA, Ross MD. The Role of MSC Therapy in Attenuating the Damaging Effects of the Cytokine Storm Induced by COVID-19 on the Heart and Cardiovascular System. Frontiers in cardiovascular medicine. 2020;7:602183.

126. Harrell CR, Fellabaum C, Jovicic N, Djonov V, Arsenijevic N, Volarevic V. Molecular Mechanisms Responsible for Therapeutic Potential of Mesenchymal Stem Cell-Derived Secretome. Cells. 2019;8(5).

127. Zhang R, Ma J, Han J, Zhang W, Ma J. Mesenchymal stem cell related therapies for cartilage lesions and osteoarthritis. American journal of translational research. 2019;11(10):6275-89.

128. Namba F. Mesenchymal stem cells for the prevention of bronchopulmonary dysplasia. Pediatrics international : official journal of the Japan Pediatric Society. 2019;61(10):945-50.

\section{Figures}




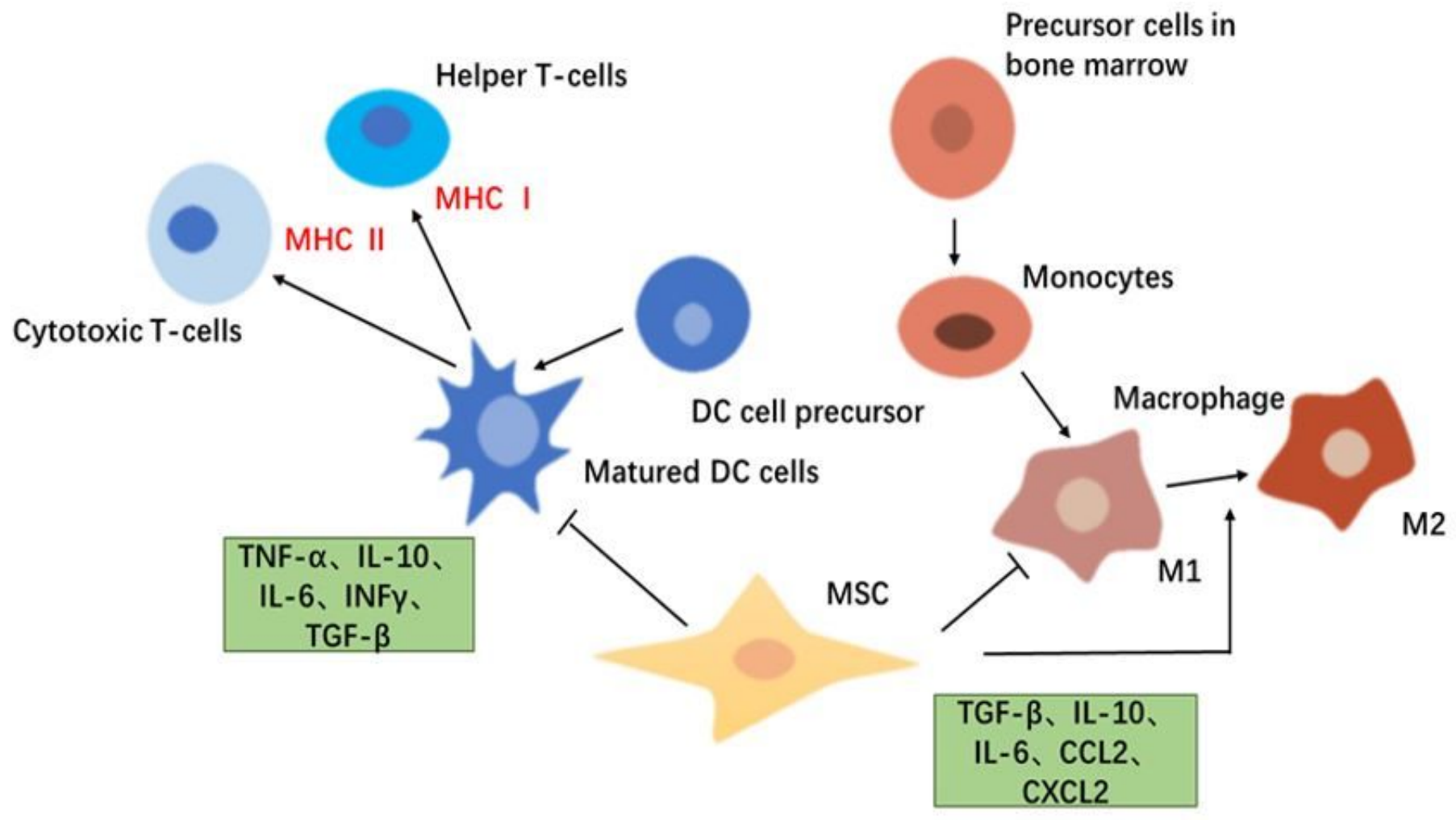

Figure 1

Macrophages are a type of Immune cells that are further differentiated from differentiated monocytes derived from bone marrow-derived precursor cells. MSCs can inhibit macrophage activation and can promote the conversion of macrophages from a pro-inflammatory M1 phenotype to an anti-inflammatory M2 phenotype. This is associated with factors such as TGF- $\beta$, IL-10, IL-6, CCL2, and CXCL2. Dendritic cells are differentiated from dendritic cell precursors and are able to regulate the conversion of $\mathrm{T}$ cells towards helper T cells as well as cytotoxic T cells. Mesenchymal stem cells can inhibit the proliferation of dendritic cells, thus affecting their regulatory T-cell function, which is associated with factors such as TNF-a, IL-10, IL-6, INF $\gamma$, and TGF- $\beta$. 


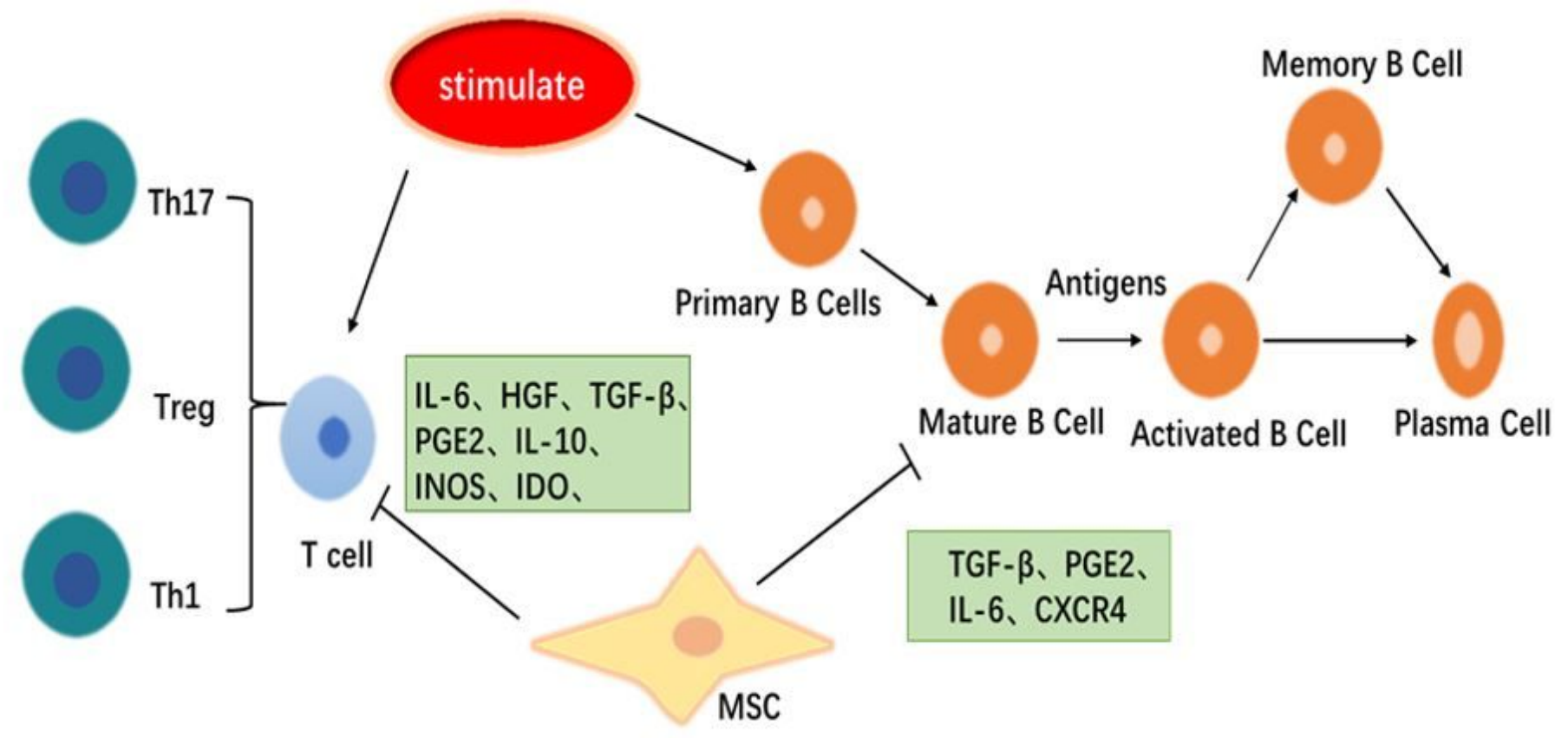

Figure 2

In the process of immune regulation, T cells can be divided into different subpopulations, such as Th1, Th7,Treg. MSCs can inhibit the proliferation and differentiation of T cells. This effect is related to the release of soluble factors such as TGF- $\beta$, HGF, IL-10, PGE-2, IL-6, INOS, IDO. Stem cells coming from bone marrow can gradually differentiate into mature $B$ cells, which, after antigenic stimulation, differentiate and proliferate into plasma cells. MSCs are also able to inhibit the proliferation of B lymphocytes and the production of antibodies, which is associated with factors such as TGF- $\beta$, PGE2, IL-6, CXCR4. MSCs can also promote the release of perforin and granzyme from NK cells, thus promoting degranulation of NK cells, which is related to TGF- $\beta$, PGE2, IL-6, IL-2 